\title{
Alarmingly high prevalence of smoking and symptoms of bronchitis in young women in Sweden: a population-based questionnaire study
}

\author{
*Göran Wennergren ${ }^{1,2}$, Linda Ekerljung', Bernt Alm², Anders Bjerg', Jan Lötvall', \\ Bo Lundbäck ${ }^{1,3}$
}

${ }^{1}$ Krefting Research Centre, Department of Medicine, University of Gothenburg, Gothenburg, Sweden
${ }^{2}$ Department of Paediatrics, University of Gothenburg, Gothenburg, Sweden
${ }^{3}$ The OLIN Studies, Department of Medicine, Sunderby Central Hospital of Norrbotten, Luleå, Sweden

Received 13th November 2012; revised 22nd January 2013; accepted 19th February 2013; 10th May 2013

\begin{abstract}
Background: After 10 years of a decrease in smoking among young people in Sweden, we now have indications of increased smoking. Aims: To provide up-to-date information on the prevalence of smoking and smoke-associated respiratory symptoms in young adults in Sweden, with a special focus on possible gender differences.

Methods: In the West Sweden Asthma Study, a detailed postal questionnaire focusing on asthma, respiratory symptoms, and possible risk factors was mailed to 30,000 randomly selected subjects aged 16-75 years. The analyses are based on responses from 2,702 subjects aged 16-25 years.

Results: More young women than men were smokers (23.5\% vs. 15.9\%; p<0.001). Women started smoking earlier and smoked more. Symptoms such as longstanding cough, sputum production, and wheeze were significantly more common in smokers. In the multiple logistic regression analysis, smoking significantly increased the risk of recurrent wheeze (odds ratio (OR) 2.0 (95\% Cl 1.4 to 3.0$)$ ) and sputum production, (OR $2.4(95 \% \mathrm{Cl} 1.9$ to 3.1$))$.

Conclusions: The alarmingly high prevalence of smoking among young women was parallel to a similarly high prevalence of bronchitis symptoms. This is worrisome, both in itself and because maternal smoking is a risk factor for illness in the child. Adverse respiratory effects of smoking occur within only a few years of smoking initiation.

(C) 2013 Primary Care Respiratory Society UK. All rights reserved.

G Wennergren et al. Prim Care Respir J 2013; 22(2): 214-220

http://dx.doi.org/10.4104/pcrj.2013.00043
\end{abstract}

Keywords asthma, bronchitis, respiratory symptoms, smoking, wheeze, young women

\section{Introduction}

The prevalence of smoking has been decreasing among Swedish teenagers since the end of the 1990s. ${ }^{1}$ However, we can now see an increase in smoking prevalence among high school teenagers. A recent investigation by the Swedish National Institute of Public Health verified this increase, which is particularly obvious among girls. ${ }^{1}$ In $15-$ year-old girls, smoking at least once a week increased from $10 \%$ in 2005-2006 to $16 \%$ in 2009-2010. ${ }^{1}$ In 2012, even higher figures were reported from the Stockholm high schools where $37 \%$ of 17 -year-old girls and $29 \%$ of boys smoked regularly. ${ }^{2}$ Similarly, recent national Swedish statistics show that the general trend of decreased smoking in the population is no longer present in young women aged 16-29 years, where daily smoking increased from $10 \%$ in 2009 to $13 \%$ in $2011 .{ }^{3}$

Smoking rates have traditionally been higher in men, but women are increasingly starting to smoke at an age equivalent to that of men. ${ }^{4}$ In the age group 15-24 years, the Global Adult Tobacco Survey (GATS) recently reported current smoking prevalence to be $29 \%$ in women and $24 \%$ in men in the UK. ${ }^{4}$ A common finding in many of the studies published in recent years is the increased smoking in young women. Smoking habits in young women thereby differ from a general trend of decreased smoking rates..$^{1,3,4}$

\footnotetext{
* Corresponding author: Professor Göran Wennergren, Department of Paediatrics, University of Gothenburg, Queen Silvia Children's Hospital, SE-416 85 Gothenburg, Sweden. Tel: +46 3134346 12, +46 705374612 Fax: +46 31843010 E-mail: goran.wennergren@pediat.gu.se
} 
The increased smoking prevalence is worrisome since smoking is related to several adverse effects on the smoker's health. In addition, the increased prevalence of smoking in teenage girls is alarming since maternal smoking during pregnancy negatively affects the offspring and increases the risk of low birth weight, sudden infant death syndrome, and wheezing illness. ${ }^{5-8}$ While many smoke-related diseases may take decades to develop, other adverse health effects such as wheeze and symptoms of bronchitis may be induced after only a few years of smoking.

The aim of this study was to provide up-to-date information on the prevalence of smoking and smoke-associated respiratory symptoms among teenagers and young adults in Sweden, with a special focus on gender differences.

\section{Methods}

\section{Study area and population}

The study area is the West Gothia Region in western Sweden including the city of Gothenburg, the second largest city in Sweden with about 800,000 inhabitants in the metropolitan area. The population of the entire region is more than 1.5 million, corresponding to one-sixth of the Swedish population.

\section{Study population and questionnaire}

In 2008 a self-administered questionnaire was mailed to 30,000 inhabitants aged $16-75$ years. A sample of 15,000 subjects was randomly selected from the metropolitan area of Gothenburg and 15,000 subjects were similarly selected from the rest of the region., ${ }^{9,10}$ The Swedish Population Register provided the names and addresses. A study of non-responders verified a good representativeness of the participants regarding respiratory symptoms and airway diseases. ${ }^{11}$ This paper is based on the 2,702 subjects aged 16-25 years who responded to the questionnaire.

The questions were based on the Swedish OLIN study questionnaire ${ }^{12-16}$ which contains items about obstructive respiratory symptoms and diseases, smoking, and other possible determinants of disease. The questionnaire was developed mainly from the British Medical Research Council questionnaire and has been used in several large-scale studies in the Nordic and Baltic countries. ${ }^{12-16}$ A comparison of the OLIN and Global Allergy and Asthma European Network (GA2LEN) questionnaires concludes that questions about bronchitis are more detailed in the OLIN questionnaire. ${ }^{17}$ Questions on common asthma symptoms are similar or identical in the two questionnaires, and they yielded similar estimates of prevalence of respiratory symptoms and diseases in the same population. ${ }^{17}$ The definitions used are presented in Box 1

The study was approved by the Ethics Committee in Gothenburg.

\section{Analyses}

Ten per cent of the data were computerised twice to check the quality of the computerisation. Errors amounted to $0.1-0.2 \%$ of the computerised data, with only a few exceptions. Statistical analyses were performed using SPSS version 18.0 (SPSS, Chicago, IL, USA). Comparisons of proportions were tested with Fisher's exact test. The Mantel-Haenszel test for trend was used where appropriate. A p value of $<0.05$ was considered statistically significant. Multiple logistic regression was used to calculate risk factors for symptoms and diseases, and risks were expressed as odds ratios (OR) with 95\% confidence intervals $(\mathrm{Cl})$.

\section{Results}

\section{Participation}

Responses were obtained from 2,702 subjects (1,548 women and

\section{Box 1. Definitions}

Smokers: reported smoking during the year preceding the survey.

Ex-smokers: reported having stopped smoking at least 12 months prior to the survey.

Never-smokers: reported neither smoking nor ex-smoking.

Physician-diagnosed asthma: "Have you been diagnosed by a doctor as having asthma?"

Asthma medication: "Do you currently use asthma medicine (permanently or as needed)?"

Attacks of shortness of breath: "Do you presently have, or have you had in the last 10 years, asthma symptoms (intermittent breathlessness or attacks of shortness of breath; the symptoms may exist simultaneously with or without a cough or wheezing)?" and "Have you had these problems within the last year?"

Longstanding cough: "Have you had a persistent cough during the last year?"

Sputum production: "Do you usually produce phlegm when you cough or do you have phlegm in your chest which is difficult to bring up?"

Recurrent wheeze: "Do you usually have wheezing or whistling in your chest when you breathe?"

Any wheeze: "Have you had whistling or wheezing in the chest on any occasion during the last 12 months?"

Wheezing with breathlessness: Yes to 'Any wheeze' and "Have you been at all breathless when you had wheezing or whistling in the chest?"

Wheezing without cold: Yes to 'Any wheeze' and "Have you had this wheezing or whistling in your chest when you did not have a cold?"

Waking with a tight chest: "Have you woken up with tightness in your chest at any time during the last 12 months?"

Allergic rhinitis: "Have you ever had allergic eye or nose problems (hay fever)?"

Nasal obstruction: "Do you have nasal blockage more or less constantly?"

Rhinorrhoea: "Do you have a runny nose more or less constantly?" 
Figure 1. Prevalence (\%) of never-smokers, ex-smokers, and smokers among men and women aged 16-25 years

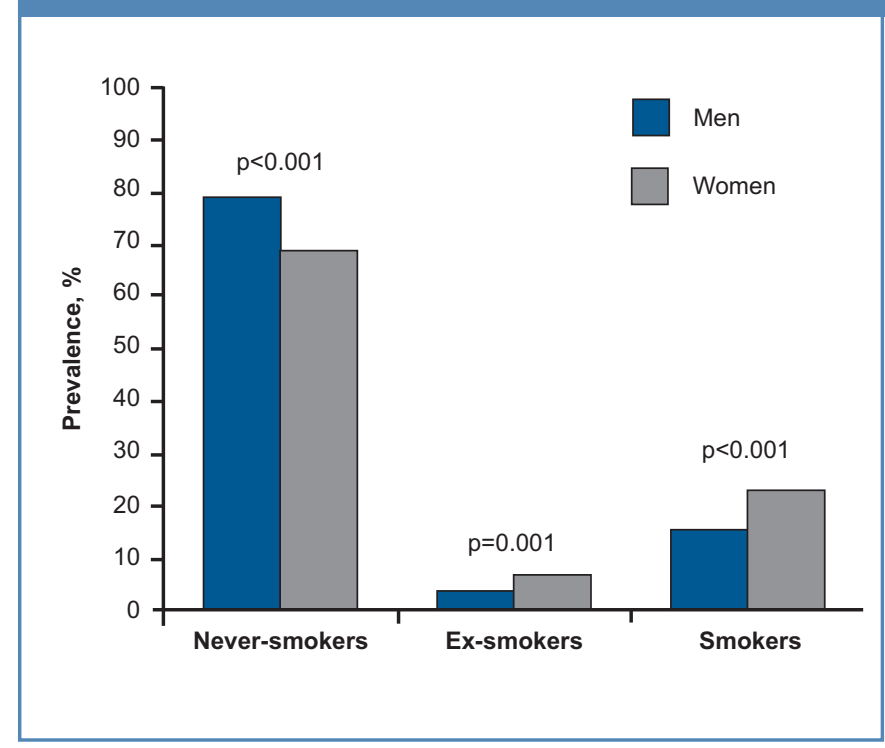

1,154 men), comprising $58.0 \%$ of the eligible women and $42.4 \%$ of the eligible men $(p<0.001)$. Of these, 1,444 lived in the metropolitan area of Gothenburg and 1,258 in the rest of the region.

The previous study of non-responders showed that male gender, young age, and smokers were over-represented among the nonresponders. ${ }^{11} \mathrm{~A}$ similar pattern was seen in the age group $16-25$ years, where $55.6 \%$ of the non-responders were men while $42.7 \%$ of the responders were men. The prevalence of smokers was $26.6 \%$ among the non-responders aged $16-25$ years compared with $20.4 \%$ in responders, with a female predominance of smokers among the nonresponders as well.

Prevalence and gender differences in smoking habits Significantly more young women than men were active smokers (23.5\% vs. $15.9 \% ; p<0.001)$ and ex-smokers $(7.2 \%$ vs. $4.1 \%$; $\mathrm{p}=0.001$ ) (Figure 1). Furthermore, the smoking women smoked significantly more than the men ( $p$ value for test for trend $<0.001$ ). Of the smoking women $42.0 \%$ smoked 5-14 cigarettes per day vs. $27.1 \%$ among the smoking men, while $10.4 \%$ vs. $6.5 \%$ smoked 15-24 cigarettes (Figure 2).

The women had also started to smoke earlier ( $p$ value for test for trend $<0.001$ ). Of the smoking women, $58.0 \%$ had started smoking between 11 and 15 years of age compared with $44.4 \%$ of the men, while $38.7 \%$ of the women reported started smoking between 16 and 20 years vs. $47.8 \%$ of men (Figure 3). The mean age at smoking initiation was 14.9 years for women and 15.8 years for men.

Differences between the metropolitan area of Gothenburg and the rest of the West Gothia region were small, although there was a slightly higher prevalence of non-smokers in the rest of the region (75.4\% vs. $71.5 \% ; p=0.025)$.

\section{Smoking status by parental smoking}

Of the subjects with smoking parents, $36.9 \%$ were smokers compared with $18.0 \%$ in subjects whose parents did not smoke $(p<0.001)$. Of all young smokers, $52.2 \%$ had smoking parents while
Figure 2. Number of cigarettes smoked per day among smoking men and women aged $16-25$ years

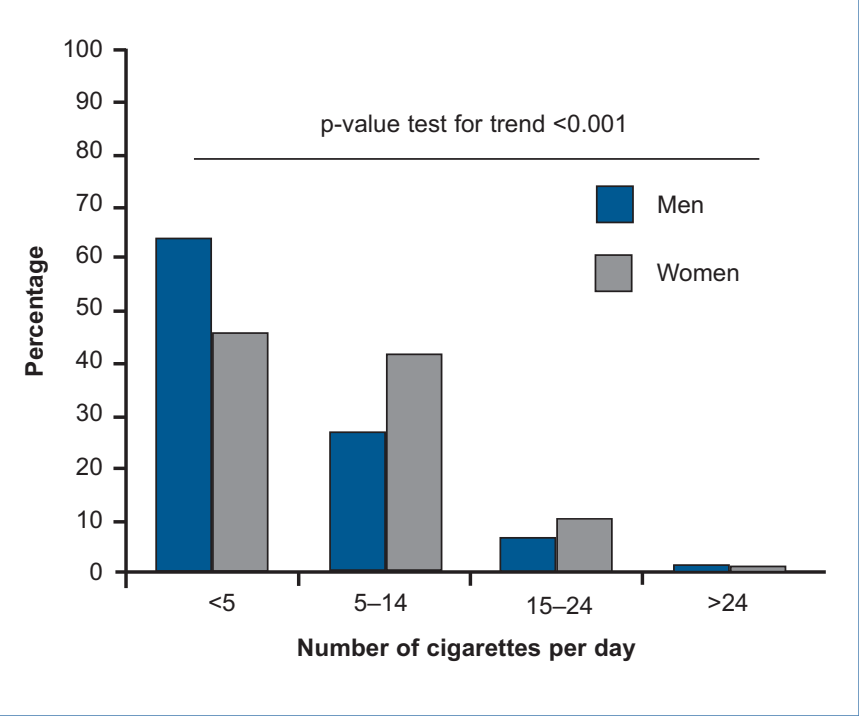

Figure 3. Age at start of smoking for men and women aged $16-25$ years

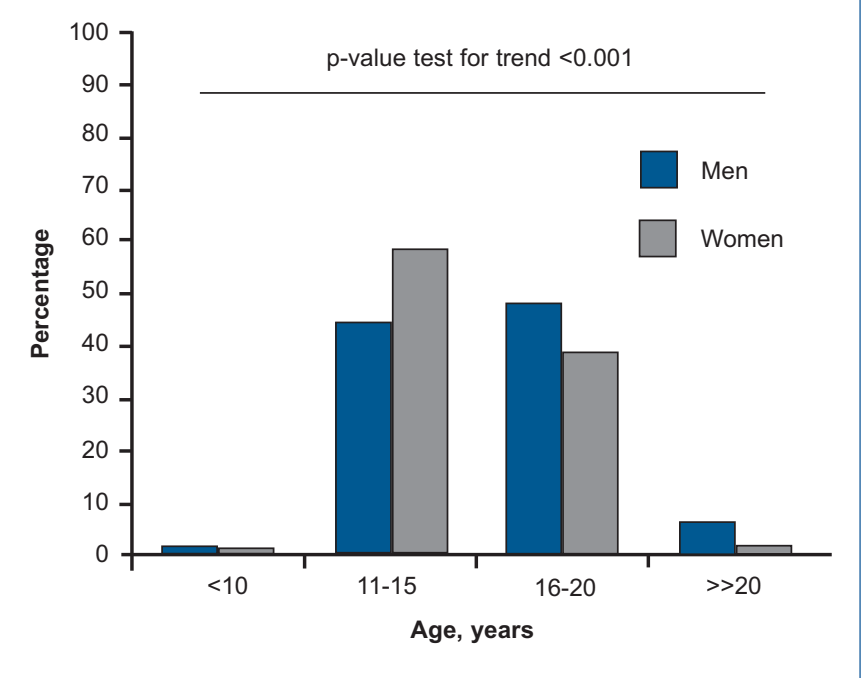

$75.4 \%$ were never-smokers among the subjects with non-smoking parents.

Prevalence of airway symptoms by smoking status

Most airway symptoms such as longstanding cough, sputum production, wheeze, waking with chest tightness, and nasal obstruction were significantly more common in smokers than in never-smokers (Table 1). This was particularly true for sputum production and longstanding cough. The overall prevalence of longstanding cough was $13.1 \%$ (15.0\% in women and $10.7 \%$ in men, $\mathrm{p}=0.001)$ and of sputum production was $15.4 \%(16.9 \%$ in women and $13.4 \%$ in men, $p=0.015$ ). The prevalence of most airway symptoms also tended to be higher among ex-smokers than among never-smokers. 
Table 1. Prevalence of physician-diagnosed asthma, asthma medication and various respiratory symptoms by smoking status

\begin{tabular}{|c|c|c|c|c|c|}
\hline & \multirow{2}{*}{$\frac{\text { Never-smokers }(n=1980)}{\%}$} & \multicolumn{2}{|c|}{ Ex-smokers $(n=158)$} & \multicolumn{2}{|c|}{ Smokers $(n=548)$} \\
\hline & & $\%$ & $\mathrm{p}$ Value & $\%$ & $\mathrm{p}$ Value \\
\hline Physician-diagnosed asthma & 9.3 & 13.3 & 0.121 & 9.5 & 0.869 \\
\hline Asthma medication & 9.0 & 10.1 & 0.666 & 9.1 & 0.933 \\
\hline Attacks of SOB in the last 12 months & 8.8 & 10.1 & 0.561 & 11.3 & 0.081 \\
\hline Longstanding cough & 10.2 & 12.0 & 0.417 & 24.1 & $<0.001$ \\
\hline Sputum production & 11.9 & 21.5 & 0.001 & 26.3 & $<0.001$ \\
\hline Recurrent wheeze & 3.9 & 7.0 & 0.093 & 8.9 & $<0.001$ \\
\hline Wheeze in the last 12 months & 13.9 & 17.7 & 0.192 & 23.9 & $<0.001$ \\
\hline Dyspnoea & 2.0 & 7.6 & $<0.001$ & 8.2 & $<0.001$ \\
\hline Wheezing with breathlessness & 9.1 & 10.8 & 0.477 & 14.1 & 0.001 \\
\hline Wheezing without a cold & 6.9 & 8.9 & 0.335 & 15.3 & $<0.001$ \\
\hline Waking with a tight chest & 8.1 & 17.1 & $<0.001$ & 13.0 & 0.001 \\
\hline Rhinitis & 28.0 & 30.4 & 0.521 & 29.2 & 0.592 \\
\hline Nasal obstruction & 16.4 & 19.0 & 0.432 & 20.8 & 0.018 \\
\hline Rhinorrhoea & 14.6 & 20.3 & 0.064 & 23.0 & $<0.001$ \\
\hline
\end{tabular}

\section{Risk factors}

In the multiple logistic regression analysis, smoking significantly increased the risk of recurrent wheeze (OR 2.0 (95\% Cl 1.4 to 3.0)) and sputum production (OR 2.4 (95\% Cl 1.9 to 3.1)) (Table 2). Similarly, occupational exposures to dust, gases, or fumes increased the risk of using asthma medication and having attacks of shortness of breath, recurrent wheeze, sputum production, and allergic rhinitis. As expected, a family history of asthma and allergy as well as female gender was associated with an increased risk of asthma medication, attacks of shortness of breath, and recurrent wheeze. When a family history of both asthma and allergy was present, the risk of using asthma medication increased six-fold (OR 6.2 (95\% Cl 4.4 to 8.9)) (Table 2).

\section{Effect modification by gender}

When we tested the interaction between gender and smoking in the same adjusted model we found statistically significant interactions (with odds ratios of about 3) between female sex and current smoking for all respiratory symptoms investigated (attacks of shortness of breath during the last 12 months OR $3.3(95 \% \mathrm{Cl} 1.3$ to 8.4$)$, recurrent wheeze OR $2.8(95 \% \mathrm{Cl} 1.1$ to 7.4$)$, and sputum production OR 3.0 (95\% Cl 1.7 to 5.2)) and for asthma medication OR 3.1 (95\% $\mathrm{Cl} 1.1$ to 8.5). However, when years of smoking or current number of cigarettes smoked daily were also included in the multiple logistic regression models, the observed interactions were no longer statistically significant.

\section{Disaussion}

\section{Main findings}

The main findings of this study are that smoking is more common among young Swedish people than expected, especially among

Table 2. Association between different independent variables and various asthma variables

\begin{tabular}{|c|c|c|c|c|c|c|}
\hline \multirow[t]{2}{*}{ Independent variables } & & \multicolumn{5}{|c|}{ Dependent variables } \\
\hline & & $\begin{array}{l}\text { Asthma } \\
\text { medication }\end{array}$ & $\begin{array}{l}\text { Attacks of } \\
\text { shortness of } \\
\text { breath }\end{array}$ & $\begin{array}{l}\text { Recurrent } \\
\text { wheeze }\end{array}$ & $\begin{array}{l}\text { Sputum } \\
\text { production }\end{array}$ & $\begin{array}{l}\text { Allergic } \\
\text { rhinitis }\end{array}$ \\
\hline \multirow{3}{*}{$\begin{array}{l}\text { Family history } \\
\text { of asthma and allergy }\end{array}$} & Asthma +, allergy - & $2.8(1.6$ to 5.0$)$ & 2.3 (1.3 to 4.2$)$ & $2.0(0.9$ to 4.2$)$ & $1.5(1.0$ to 2.4$)$ & $0.8(0.5$ to 1.4$)$ \\
\hline & Asthma -, allergy + & 2.3 (1.6 to 3.4$)$ & 2.2 (1.5 to 3.2$)$ & $1.4(0.8$ to 2.3$)$ & $1.2(0.9$ to 1.6$)$ & $5.4(4.3$ to 6.7$)$ \\
\hline & Asthma + , allergy + & 6.2 (4.4 to 8.9$)$ & 5.6 (4.0 to 8.0$)$ & $4.5(2.9$ to 7.0$)$ & $2.2(1.7$ to 2.9$)$ & 9.1 (7.0 to 11.7$)$ \\
\hline Gender & Female & $1.6(1.2$ to 2.2$)$ & 1.8 (1.4 to 2.5$)$ & 1.6 (1.1 to 2.4$)$ & $1.2(0.9$ to 1.5$)$ & $0.9(0.8$ to 1.1$)$ \\
\hline \multirow[t]{2}{*}{ Smoking habit } & Ex-smokers & $1.1(0.6$ to 1.9$)$ & $1.1(0.6$ to 1.8$)$ & $1.5(0.8$ to 3.0$)$ & $1.9(1.3$ to 2.9$)$ & $1.1(0.7$ to 1.6$)$ \\
\hline & Smokers & $0.9(0.6$ to 1.2$)$ & $1.1(0.8$ to 1.5$)$ & $2.0(1.4$ to 3.0$)$ & $2.4(1.9$ to 3.1$)$ & $1.0(0.8$ to 1.2$)$ \\
\hline Urban childhood & Yes & $1.4(1.0$ to 1.9$)$ & $1.3(1.0$ to 1.8$)$ & $1.0(0.7$ to 1.5$)$ & $1.3(1.0$ to 1.7$)$ & $1.1(0.9$ to 1.3$)$ \\
\hline Occupational exposure & Yes & 1.5 (1.03 to 2.0$)$ & $1.6(1.2$ to 2.2$)$ & $2.2(1.5$ to 3.2$)$ & $1.5(1.1$ to 1.9$)$ & $1.5(1.2$ to 1.9$)$ \\
\hline
\end{tabular}

Odds ratios (ORs) with $95 \%$ confidence intervals $(95 \% \mathrm{Cl}$ ) were calculated using multiple logistic regression analysis. The statistical model also included degree of urbanisation. Bold values indicate statistically significant ORs. 
young women, and that adverse respiratory effects are seen after only a few years of smoking. Women start smoking earlier and smoke more. The prevalence of bronchitis symptoms is alarmingly high, with one out of four reporting longstanding cough and sputum production. In the multiple logistic regression analysis, smoking significantly increased the risk of recurrent wheeze and sputum production

\section{Interpretation of findings in relation to previously published work}

Our findings are in line with recent statistics from the Swedish National Institute of Public Health. ${ }^{1}$ In that survey, the prevalence of smoking in 15-year-old girls was 16\% in 2009-2010 compared with $10 \%$ in 2005-2006, while the corresponding prevalence in boys was $13 \%$ and $8 \%$. In Northern Sweden, in 2003, the prevalence of smokers among 15-year-old teenagers was even lower (9\% of girls and only $3 \%$ of boys). ${ }^{18}$ The prevalence of active smoking in our study was even higher in the age group $16-25$ years $(23.5 \%$ in women and $15.9 \%$ in men).

The study in Northern Sweden also showed that significantly more young women than young men smoke. ${ }^{18} \mathrm{~A}$ similar pattern is seen in Norway. ${ }^{19}$ Furthermore, in our study, the women also started smoking earlier than the men. On the other hand, the use of snuff is more common among young men. ${ }^{18}$

Although smoking has decreased since 1990 when the overall smoking prevalence among adults aged 20-44 years in Sweden was $30-40 \%,{ }^{20}$ we were surprised by the high smoking prevalence we found among young women. The present smoking prevalence is, in fact, comparable to that found in a study in Northern Sweden in $1996 .{ }^{21}$ In that study, smoking in the age group 20-29 years was $26 \%$ among women and $16 \%$ among men. This contradicts a general conception of a clear-cut decrease in smoking prevalence during the last 10-15 years among young adults. Recent longitudinal Swedish surveys report an increased smoking prevalence in young women in the last years. ${ }^{1,3}$ The present results are in line with those reports. However, since the present study reports data from a single survey and compares the findings with other studies, we cannot conclude that the study itself shows an increased prevalence of smoking.

Female smoking dominance is not seen in all countries - for example, in Finland and Estonia smoking is more common among young men. ${ }^{15,22}$ In middle-income and low-income countries, smoking rates are higher in men. ${ }^{4}$ However, as pointed out in the GATS survey, women in those countries also start to smoke at an early age. ${ }^{4}$ With increasing economic growth, a development similar to that in high-income countries could be expected, with the smoking prevalence becoming higher in women.

Smoking parents is a strong risk factor for the child to become a smoker. Smoking among teenagers is twice as common among those with at least one smoking parent compared with those with no parent who smokes. ${ }^{23}$

The overall prevalence of respiratory symptoms (13-15\%) with a significant female dominance was higher than that reported in subjects of similar age in a large-scale Swedish study performed 19 years before our study. ${ }^{24}$ That study used identical questions about symptoms and yielded an overall prevalence, including smokers, of
10-12\%. A Swedish study among teenagers performed in 1987 found the prevalence of longstanding cough to be 3-5\%. ${ }^{25}$ The Swedish part of the European Community Respiratory Health Survey (ECRHS) with an age distribution from 20 up to 44 years did not report prevalence by age group, but the overall prevalence of bronchitis symptoms was similar to ours, although our study sample was considerably younger. ${ }^{20}$ As symptoms of bronchitis tend to increase with age, ${ }^{12,24}$ a comparison with the ECRHS results also suggests an increase in young subjects.

Smoking was associated with most respiratory symptoms. Indices of the adverse effects of smoking, such as a longstanding cough and sputum production, are already seen at this young age. The results show that adverse effects of smoking appear in a surprisingly short time and call attention to the short-term consequences for young people. The association with recurrent wheeze and sputum production remained after adjustment for other risk factors for respiratory symptoms.

In the same adjusted model there were clear interactions between female sex and current smoking for all asthma symptoms investigated. These findings are in line with several studies indicating an increased susceptibility to tobacco smoke among women. ${ }^{26,27}$ However, in our study, the stronger effect of smoking in women on sputum production and recurrent wheeze seemed to be explained by women starting earlier and smoking more.

The fact that smoking is common today in young women and that there are indications of increased smoking in young women is particularly worrying. ${ }^{1,3}$ Maternal smoking during pregnancy is a well-known risk factor for wheezing illness and bronchial hyperresponsiveness in the child. ${ }^{7,8}$ The effects in terms of increased risk of asthma and impaired lung function are longstanding and may be seen even up to adulthood. ${ }^{28-31}$ Furthermore, exposure to environmental tobacco smoke during childhood is associated with an increased prevalence of asthma in adults. ${ }^{32}$ Growing up with smoking parents increases the risk of the child becoming an active smoker, which in turn is a risk factor for respiratory symptoms and asthma. ${ }^{28,33}$ Hence, a vicious circle is established.

An explanation for the high smoking prevalence among young women could be that, today, girls and young women tend to adopt the cigarette and alcohol habits previously seen among boys and young men. In addition, some girls are attracted by the side-effect that smoking makes it easier for them to stay slim. Smoking in Sweden is closely linked to a low level of education and lower socioeconomic status. ${ }^{3}$ As in several other European countries, Sweden has in recent years faced problems with youth unemployment which could contribute to the high smoking prevalence seen. Another factor could be an influence by secondgeneration immigrants who come from cultures with a high prevalence of smokers. Just as smoking parents is a strong risk factor for the child to start smoking, we know that teenagers are influenced by the smoking habits of their friends.

Implications for future research, policy and practice The findings highlight the importance of long-term efforts and openness to the continuously changing forces that drive smoking initiation in the young. Maternity care in Sweden has nearly full coverage and represents an important opportunity to convince 
parents-to-be to quit smoking in light of the health risks in the unborn child. Moreover, smoking parents also have the possibility to influence their children not to smoke. However, it requires an active effort by the parents and a discussion of the adverse effects of tobacco, and smoking parents could thus be a key group on which to focus future anti-smoking efforts.

One practical measure that could be taken to counteract the worrying trend is a rise in the price of tobacco. The $\mathrm{WHO}$ convention on tobacco control points out that price and tax measures are effective and important means of reducing tobacco consumption among young persons in particular. ${ }^{34}$ In the 1990 s the health risk of smoking was regularly discussed in Swedish schools. During the last decade, however, this practice has subsided. Our study highlights the importance of schools as a primary vehicle for tobacco awareness among children.

\section{Strengths and limitations of the study}

The strengths of the study include the population-based design and the large study sample. Another strength is the well-established questionnaire used, with questions that thoroughly cover smoking and symptoms of bronchitis and obstructive airway disease.

Weaknesses of the study are those inherent in questionnairebased studies - namely, some uncertainty regarding the validity of answers. However, it is unlikely that the study participants exaggerated their smoking. Instead, it is more likely that smoking is underestimated in the answers. Furthermore, this part of the West Sweden Asthma Study did not include lung function testing. Another limitation of the study is the non-response rate. The previous study of non-responders ${ }^{11}$ was therefore supplemented with an analysis that verified that smoking was also somewhat more common among non-responders in the age group 16-25 years, especially among the women. Thus, our results, if anything, underestimate the prevalence of smokers. Furthermore, since smoking was also more common in women among the nonresponders, the lower response rate in men probably does not pose an issue in interpreting the findings.

\section{Conclusions}

The high prevalence of smoking among young women found in this study is worrying, both in itself and since smoking is a risk factor for illness in the children of smoking women. In addition to a higher smoking prevalence, the women started smoking earlier and smoked more than the men. Adverse respiratory effects were seen after only a few years of smoking. The association between smoking and recurrent wheeze and sputum production remained after adjustment for other risk factors for respiratory symptoms. Compared with the results of previous studies in people of similar ages, a higher prevalence of bronchitis symptoms was found. The results call for continuous anti-smoking efforts. Effective smoking prevention programmes, particularly among young women, are needed.

\section{Handling editor David Bellamy Statistical review Gopal Netuveli}

Conflicts of interest The authors declare that they have no conflicts of interest in relation to this article.

Contributorship All co-authors made substantial contributions to the study. BL and JL designed the West Sweden Asthma Study. LE had the main responsibility for the statistical calculations. GW and BL had the main responsibility for writing the manuscript. All co-authors contributed to the editing of the manuscript and approved the submitted version of the paper. GW and $\mathrm{BL}$ are guarantors of the study.

Funding The study was supported by the VBG Group Herman Krefting Foundation for Asthma and Allergy Research, the Swedish Heart Lung Foundation, the Sahlgrenska Academy at the University of Gothenburg, the Research Foundation of the Swedish Asthma and Allergy Association, and the Health \& Medical Care Committee of the Regional Executive Board, Västra Götaland Region.

\section{References}

1. Swedish National Institute of Public Health [Statens folkhälsoinstitut]. Health Behaviour in School-aged Children (HBSC), results from Sweden of the 2009/10 WHO study [Svenska skolbarns hälsovanor 2009/10. Grundrapport]. R 2011:27, Östersund, Sweden, 2011. http://www.fhi.se/PageFiles/12995/R2011-27-Svenskaskolbarns-halsovanor-2009-2010-grundrapport.pdf (accessed 5 Nov 2012).

2. City of Stockholm. The Stockholm questionnaire 2012 [Stockholmsenkäten 2012]. Stockholm, Sweden, 2012. http://www.stockholm.se/Fristaende-webbplatser/ Fackforvaltningssajter/Socialtjanstforvaltningen/Utvecklingsenheten/Prevention/Stock holmsenkaten1/ (accessed 5 Nov 2012).

3. Swedish National Board of Health and Welfare [Socialstyrelsen], Swedish National Institute of Public Health [Statens folkhälsoinstitut]. Public health in Sweden: Annual report 2012 [Folkhälsan i Sverige: Årsrapport 2012]. Stockholm and Östersund, Sweden, 2012. http://www.socialstyrelsen.se/Lists/Artikelkatalog/Attachments/ 18623/2012-3-6.pdf (accessed 5 Nov 2012).

4. Giovino GA, Mirza SA, Samet JM, et al. Tobacco use in 3 billion individuals from 16 countries: an analysis of nationally representative cross-sectional household surveys. Lancet 2012;380(9842):668-79. http://dx.doi.org/10.1016/S0140-6736(12)61085-X

5. Brooke OG, Anderson HR, Bland JM, Peacock JL, Stewart CM. Effects on birthweight of smoking, alcohol, caffeine, socioeconomic factors, and psychosocial stress. BMJ 1989;298(6676):795-801. http://dx.doi.org/10.1136/bmj.298.6676.795

6. Alm B, Milerad J, Wennergren $G$, et al. A case-control study of smoking and sudden infant death syndrome in the Scandinavian countries, 1992 to 1995. Arch Dis Child 1998;78(4):329-34. http://dx.doi.org/10.1136/adc.78.4.329

7. Stein RT, Holberg CJ, Sherrill D, et al. Influence of parental smoking on respiratory symptoms during the first decade of life: the Tucson Children's Respiratory Study. Am J Epidemiol 1999;149(11):1030-7.

http://dx.doi.org/10.1093/oxfordjournals.aje.a009748

8. Gilliland FD, Li YF, Peters JM. Effects of maternal smoking during pregnancy and environmental tobacco smoke on asthma and wheezing in children. Am J Respir Crit Care Med 2001;163(2):429-36. http://dx.doi.org/10.1164/ajrccm. 163.2.2006009

9. Lötvall J, Ekerljung L, Rönmark EP et al. West Sweden Asthma Study: prevalence trends over the last 18 years argue no recent increase in asthma. Respir Res 2009;10:94. http://dx.doi.org/10.1186/1465-9921-10-94

10. Ekerljung L, Bossios A, Lötvall J, et al. Multi-symptom asthma as an indication of disease severity in epidemiology. Eur Respir J 2011;38(4):825-32. http://dx.doi.org/10.1183/09031936.00143710

11. Rönmark EP, Ekerljung L, Lötvall J, Torén $K$, Rönmark $E$, Lundbäck B. Large scale questionnaire survey on respiratory health in Sweden: effects of late- and nonresponse. Respir Med 2009;103(12):1807-15. http://dx.doi.org/10.1016/j.rmed.2009.07.014

12. Lundbäck B, Nyström L, Rosenhall L, Stjernberg N. Obstructive lung disease in northern Sweden: respiratory symptoms assessed in a postal survey. Eur Respir $J$ 1991:4(3):257-66.

13. Kotaniemi J, Lundbäck $B$, Nieminen $M$, Sovijärvi A, Laitinen L. Increase of asthma in adults in Northern Finland - a report from the FinEsS study. Allergy 2001;56(2):16974. http://dx.doi.org/10.1034/j.1398-9995.2001.056002169.x

14. Meren M, Jannus-Pruljan L, Loit HM, et al. Asthma, chronic bronchitis and respiratory symptoms among adults in Estonia. Respir Med 2001;95(12):954-64. http://dx.doi.org/10.1053/rmed.2001.1188

15. Pallasaho $P$, Lundbäck $B$, Meren $M$, et al. Prevalence and risk factors for asthma and chronic bronchitis in the capitals Helsinki, Stockholm, and Tallinn. Respir Med 2002;96(10):759-69. http://dx.doi.org/10.1053/rmed.2002.1308

16. Ekerljung L, Rönmark E, Larsson K, et al. No further increase of incidence of asthma: incidence, remission and relapse of adult asthma in Sweden. Respir Med 2008;102(12):1730-6. http://dx.doi.org/10.1016/j.rmed.2008.07.011 
17. Ekerljung L, Rönmark E, Lötvall J, Wennergren G, Torén K, Lundbäck B. Questionnaire layout and wording influence prevalence and risk estimates of respiratory symptoms in a population cohort. Clin Respir J 2013;7(1):53-63. http://dx.doi.org/10.1111/j.1752-699X.2012.00281.x

18. Hedman L, Bjerg A, Perzanowski M, Sundberg S, Rönmark E. Factors related to tobacco use among teenagers. Respir Med 2007;101(3):496-502. http://dx.doi.org/10.1016/j.rmed.2006.07.001

19. Tollefsen E, Bjermer L, Langhammer A, Johnsen R, Holmen TL. Adolescent respiratory symptoms - girls are at risk: the Young-HUNT study, Norway. Respir Med 2006;100(3):471-6. http://dx.doi.org/10.1016/j.rmed.2005.06.007

20. Björnsson E, Plaschke P, Norrman E, et al. Symptoms related to asthma and chronic bronchitis in three areas of Sweden. Eur Respir J 1994;7(12):2146-53. http://dx.doi.org/10.1183/09031936.94.07122146

21. Lindström M, Kotaniemi J, Jönsson E, Lundbäck B. Smoking, respiratory symptoms, and diseases: a comparative study between northern Sweden and northern Finland: report from the FinEsS study. Chest 2001;119(3):852-61.

http://dx.doi.org/10.1378/chest.119.3.852

22. Pallasaho $P$, Juusela $M$, Lindqvist $A$, Sovijärvi $A$, Lundbäck $B$, Rönmark E. Allergic rhinoconjunctivitis doubles the risk for incident asthma - results from a population study in Helsinki, Finland. Respir Med 2011;105(10):1449-56. http://dx.doi.org/10.1016/j.rmed.2011.04.013

23. Swedish National Institute of Public Health [Statens folkhälsoinstitut]. Teenagers on tobacco 2009 - habits, knowledge and attitudes [Tonåringar om tobak - vanor, kunskaper och attityder]. R 2010:20, Östersund, Sweden, 2010. http://www.fhi.se/PageFiles/10883/R-2010-20-Tonaringar-om-tobak.pdf (accessed 5 Nov 2012).

24. Larsson L, Boëthius G, Uddenfeldt M. Differences in utilization of asthma drugs between two neighbouring Swedish provinces: relation to symptom reporting. Eur Respir J 1993;6(2):198-203.

25. Norrman E, Rosenhall L, Nyström L, Bergström E, Stjernberg N. High prevalence of asthma and related symptoms in teenagers in Northern Sweden. Eur Respir $J$ 1993;6(6):834-9.
26. Xu X, Li B, Wang L. Gender difference in smoking effects on adult pulmonary function. Eur Respir J 1994;7(3):477-83. http://dx.doi.org/10.1183/09031936.94.07030477

27. Langhammer A, Johnsen R, Holmen J, Gulsvik A, Bjermer L. Cigarette smoking gives more respiratory symptoms among women than among men. The Nord-Trondelag Health Study (HUNT). J Epidemiol Community Health 2000;54(12):917-22. http://dx.doi.org/10.1136/jech.54.12.917

28. Goksör E, Åmark M, Alm B, Gustafsson PM, Wennergren G. The impact of pre- and post-natal smoke exposure on future asthma and bronchial hyperresponsiveness. Acta Paediatr 2007;96(7):1030-5 http://dx.doi.org/10.1111/j.1651-2227.2007.00296.x

29. Goksör E, Gustafsson PM, Alm B, Åmark M, Wennergren G. Reduced airway function in early adulthood among subjects with wheezing disorder before two years of age. Pediatr Pulmonol 2008;43(4):396-403. http://dx.doi.org/10.1002/ppul.20798

30. Piippo-Savolainen E, Korppi M. Wheezy babies - wheezy adults? Review of long-term outcome until adulthood after early childhood wheezing. Acta Paediatr 2008;97(1):5-11. http://dx.doi.org/10.1111/j.1651-2227.2007.00558.x

31. Bjerg A, Hedman L, Perzanowski M, Lundbäck B, Rönmark E. A strong synergism of low birth weight and prenatal smoking on asthma in schoolchildren. Pediatrics 2011;127(4):e905-12. http://dx.doi.org/10.1542/peds.2010-2850

32. Larsson ML, Frisk M, Hallström J, Kiviloog J, Lundbäck B. Environmental tobacco smoke exposure during childhood is associated with increased prevalence of asthma in adults. Chest 2001;120(3):711-7. http://dx.doi.org/10.1378/chest.120.3.711

33. Hedman L, Bjerg A, Sundberg S, Forsberg B, Rönmark E. Both environmental tobacco smoke and personal smoking is related to asthma and wheeze in teenagers. Thorax 2011;66(1):20-5. http://dx.doi.org/10.1136/thx.2010.143800

34. World Health Organization. WHO Framework Convention on Tobacco Control. Geneva, Switzerland, 2003. Updated 2004, 2005. http://whqlibdoc.who.int/publications/2003/9241591013.pdf (accessed 22 Jan 2013).

\section{Available online at http://www.thepcrj.org}

